\title{
The Rise of Culinary Tourism and Its Transformation of Food Cultures: The National Cuisine of Taiwan
}

\author{
Hui-Tun CHUANG
}

\begin{abstract}
The rise of culinary tourism reflects political and economic transformations in Taiwan. This paper examines the relationship between the anxiety of the identity crisis that is bubbling up in Taiwan and the way in which dietary culture becomes an important part of identity practice. Traditional Taiwanese cuisine has recently been given new recognition through the practice of culinary tourism. Previously disappearing ethnic foods have regained visibility in the haute cuisine market. The trend of ethnic cuisine restoration is a worldwide phenomenon; yet, in the Taiwanese case, it is unique because the particular food consumption pattern reflects the reconstruction of national identity as a significant reaction to previous colonial experiences and the globalization of food cultures. By analyzing the political transformations of the nation-state at macroscale and the social phenomenon of food cultures at microscale, I will illustrate the social milieu that accounts for the changing cultural images of Taiwanese foods, as well as the way in which cultural identity is fashioned by producing and consuming these cultural images.
\end{abstract}

Keywords: Taiwanese food, culinary tourism, class politics, identity transformation

\section{Introduction}

In recent years, Taiwan has become widely recognized as a 'food paradise', seducing both foreign and domestic tourists with the promise of a unique cultural and gastronomic experience. While the phenomenon of culinary tourism is becoming more popular in Taiwan, its continued growth requires conditions favourable to a new appreciation for local culture, one that is emerging in response to an increasingly global society and a developing Taiwanese national identity. As the product of political and social efforts by the government, mass media and tourism industry, the development of culinary tourism is as much a matter of political economy as it is of culture, as evidenced by two intertwined and reinforced premises: on the one hand, culinary products are increas- 
ingly seen as important symbols of a society's culture and heritage; on the other hand, culinary tourists are essentially interested in consuming cultures rather than in ordinary leisure experiences. In a sense, culinary tourism as an international and intra-social cultural practice plays a role in generating economic interests well beyond the tourism industry. Additionally, the government's agenda attempts to position culinary tourism as a fashionable activity within Taiwanese society, while at the same time raising the nation's visibility on an international scale. These efforts have made the production and consumption of indigenous food a significant Taiwanese cultural trait.

In comparison with other societies, the complexity of Taiwanese food culture cannot be understood as merely the array of foods and food activities of which it is composed. Rather, it is found in the very subtle ways in which these foods and activities embody political and social implications. Hence, in exploring the increased visibility and social rediscovery of Taiwanese national cuisine, my research will involve investigation on three intersecting trajectories: (1) the transformation of Taiwanese-ness from a local to a national scale, (2) the increased visibility of Taiwanese food as a mapping-out of its authenticity and uniqueness in the floating culinary market for domestic as well as international tourists and (3) the change in the social stratification of Taiwanese foods in response to the demand for a national cuisine.

In the first trajectory, I will regard the notion of Taiwanese-ness as not inherently bound to a specific space and time in the indigenous society. Rather, it has undergone a number of indigenization and self-affirmation processes, transforming identity when required by societal needs.

Second, the visibility of Taiwanese foods is not self-generated, but increased by external political and economic forces, such as a heightened intra-social consciousness or the stimulation of global competition. In order to understand how Taiwanese food culture reflects these societal complexities and political implications, I need to examine how the political transformations in twenty-first-century Taiwan would call for food culture to function as a conceptual aid to localism and nationalism. In contrast to other post-colonial countries, the political transformation in Taiwan has been relatively efficient; however, it does suffer from ethnic conflicts and political uncertainty on the question of nationhood, which cause the issue of national identity to remain uncertain. In a sense, the Taiwanese case is unique in the context of global society due to its colonial history and post-colonial condition. Questions remain as to whether the appropriation of this idea - the preservation of local 
culture-arises as a form of resistance to global culture and economy, or whether the ideas of localism and nationalism are, on the contrary, used by Taiwanese authorities as globalization strategies to resolve economic crises. In addition, it will be productive to articulate the relationship between culinary tourism and national identity formation, as the food cultures practiced in daily life could be considered subtle forms of resistance to the long predomination of Chinese culture since 1945. As a consequence, the popularization of culinary tourism implies that such a cultural tactic is effective and creates opportunities for the redefinition and rediscovery of local and authentic foods.

Finally, in a broader social context, I will examine how foods entail symbolic order and hierarchical social meanings. Indeed, the meanings of foods can never remain fixed. In Taiwan's case, the production and consumption of foods' meaning involves the multifaceted processes of intra- and inter-social differentiation, the criteria for which are shifting from ethnic-oriented to market-oriented. The development of culinary tourism expresses this transformation, and also results in a change in the categories of haute cuisine and bas cuisine. In a sense, I argue that the culinary tourism might act as a social institution to mutate social statuses of foods at large.

In order to map out these three trajectories, I employ ethnographic research, including participant observation at the restaurants of the Grand Hotel, the food court in Taipei 101 building, Kaohsiung's Liuho International Tourism Night Market and Raohe Street Night Market in Taipei, as well as interviews with food vendors, restaurant managers, chefs and customers. Articles about 'Taiwanese' foods and restaurant reviews from mass media, tourist guidebooks and cookbooks are taken as references to approach ways in which the authenticity of Taiwanese foods is socially constructed; upon further analysis these resources also introduce the notion that consumer autonomy and human agency may be problematic in generating desire that is overwhelmingly stimulated by mass media, and as a consequence, the practice of food consumption is misguided.

The relationship between Taiwanese foods and Taiwanese identity will be explored in this paper, with the purpose of illuminating the reciprocal processes of national identity formation: the externalization of Taiwanese national identity through the production and the consumption of foods as a function of culinary tourism, and the internal self-affirmation of Taiwanese-ness through the redefinition of quotidian and indigenous foods as significant cultural symbols for the nation-state. 


\section{The Rediscovery of Taiwanese Food as Native, Authentic and National}

The term 'native foods' commonly refers to the specific ethnic communities and places in which food cultures are practiced in aspects of both production and consumption. Before discussing Taiwanese food, I would like to clarify such seemingly coterminous concepts as native, local, authentic and national, all of which I allocate to the broader category of 'Taiwanese-ness'. To be sure, the words 'local' and 'native' carry various meanings which should not be treated as having a unity in the fixed geography; rather, the concepts of locality and indigeneity from the regional studies and political geography perspectives seem inherent by virtue of their being bound within a predetermined space. However, as far as this work is concerned, the concept of locality is not only associated with space but also with time. In other words, the 'local' should be defined both by the alterity of its spatial relationship and its context in a transitional history. The concepts of locality are in some sense always floating because they are the products of time-space imagination (Anderson 1983). In a sense, it is problematic if the concept of Taiwanese-ness is founded on homogenous and essentialist grounds, without historical contextualization.

Taiwanese-ness currently refers to a national identity in opposition to Chinese identity. Ironically, Taiwanese-ness was never taken into account as a political and cultural characteristic of the nation-state until the late 1990s. Since 1945, when Kuo-Ming Dong (Chinese Nationalist Party) took over control of Taiwan from the Japanese colonial authorities, Taiwan's colonial experiences were disregarded as merely a history of enslavement that needed to be supplanted by Chinese culture at large. For the Taiwanese, this post-colonial condition served as an endorsement of 'colonization' by the Chinese Nationalist Party. The transformation of the Taiwanese people's political and cultural identity was taken as a priority policy by both the central and local governments, in accordance with the ideology of Chinese Nationalist domination from 1945 to 2000.

The relationship between the Taiwanese and Chinese national identities is very ambiguous. Due to the fact that the island's early settlers came mostly from China during the seventeenth century, China was viewed as 'the Motherland'. Taiwanese people considered themselves ethnically 'Chinese', known as the ethnic Han, especially during Japanese colonization. The affiliation with Chinese culture and ethnicity was even reinforced by the Japanese authorities in order to distinguish the 
colonizers from the colonized during the early colonial period (Ching 2001: 7). Paradoxically, though this Chinese ethnic affiliation was employed to support opposition and resistance to the Japanese throughout the colonial period, a spirit of Taiwanese-ness also emerged as a result of this resistance, and was a source of great debate (Ching 2001). This emerging Taiwanese identity had nearly reached a point of maturity when it was terminated and purposely annihilated by Chinese Nationalist domination (Fleischauer 2007).

What is Taiwanese-ness? The identification process requires alterity to outline the boundaries within which self-affirmation takes place. Without analyzing how this identification process is undertaken, it cannot be simply stated that the Japanese were the outsiders and that the Chinese identity is shifting its role from that of the insider to that of the outsider. This shift attracts further sociological investigation. By observing the political transformation in Taiwan, I found that the relationship between the Chinese and Taiwanese identities is changing. On the vertical axis, a dominant/subordinate relationship was created to distinguish a superior Chinese culture from an inferior Taiwanese culture. However, this relationship has shifted to a parallel one in which the definition of 'Taiwanese' is taken to include Chinese immigrants as natives. Taiwanese-ness has been intentionally upgraded to the level of a national characteristic, and its ultimate criteria contain all of the past, present and emerging immigrant cultures. The foods of Chinese immigrants, for instance, have been indigenized and been deemed as one style of Taiwanese cuisine. This tendency is obviously shown in the recent published cookbooks and gourmand reviews by the authors who mostly originate from the Mainlander group, and who attempt to re-interpret the characteristics of Chinese immigrants' foods from Chian Chuan (the villages of mainlander military dependents). For example, Chian Chuan's food is deemed a special Taiwanese local gastronomy by Wang Wei-Chung whose family story illustrates the complexity of social interaction in the postwar Taiwan where the inter-marriage between various ethnic groups took place in the villages. This naturally brought up the exchange of gastronomic ideas and the fusion of foods (Wang 2008).

As far as Taiwanese national food is concerned, we must first of all admit the premise that food acts as a representative of the cultural roots of nationalism (Appadurai 1988; Pilcher 1998; Cusack 2000). Indeed, 'every nation has its own cuisine' (Cusack 2000: 207), which has been gradually accepted and becomes a taken-for-granted culinary ideology 
in the contemporary society. Reay Tannahill, a Scottish historian, asserts that 'culturally defined food choices and patterns of eating came to be seen as "characteristic" of a people and country' (Palmer 1998: 187; Igor 2000: 209). Recently, many countries have attempted to redefine their own national cuisines and culinary cultures. The Indian curry dishes, chicken tikka massala and vindaloo (Cook 2001) are examples of foods that to some represent truly British national dishes and have in this role replaced such British standards as fish and chips and roast beef. Similarly, Taiwanese officials have made an effort to serve a popular street food, the bowl-pasties called wa-guei, at national banquets, instead of a traditional Chinese dish such as Yang-chow fried noodles. This phenomenon indicates that the above ideology has been widely adopted.

Food's capacity to act as a symbol has been recognized and highly admired in the Taiwanese post-colonial context, in which people encounter the problem of a floating identity as a result of the previous colonial experiences, the contradiction between Chinese and Taiwanese identities and increasing globalization.

Compared to other cultural activities, e.g. the fashion industry, architecture and art, food is playing a relatively prominent role in the representation of Taiwanese national identity. Food production and consumption are strongly associated with both the agricultural economy and the tourism industry, and might not be employed to assert Taiwanese identity without such economic advantages. Like other developing counties, Taiwan faced an economic crisis during the 1980s and 1990s that caused most of its industry to move to South Asia and China. As a consequence, the government started to get involved in economic transformation after a serious political reformation. The transformation of agriculture and the promotion of tourism on a national scale have been pursued as alternatives for resolving the ailing economy and environmental deterioration within the country. The fact that Taiwanese authorities have applied such a win-win strategy for economic development obviously indicates that the social quest for Taiwanese foods is involved in the complex process of politicaleconomic transformation and social re-integration.

\section{Social Stratification of Food in Taiwan}

When speaking of Taiwanese foods, people commonly have a taken-forgranted image of food sold by street vendors in their minds. Taiwan's peculiar political and ethnic hierarchy has a counterpart in the ranking 
of culinary taste and cooking. Generally speaking, native Taiwanese food has been assigned a lower position, insofar as gastronomic and aesthetic values are concerned. Tracking this pattern historically reveals that the common prejudice against what is deemed unhygienic and indecent in Taiwanese cuisine began during the Japanese colonial period (1895-1945). The Japanese colonizers criticized Taiwan's local markets as filthy and grimy, and considered native foods unhealthy (Shiunaigashi 1909). As is characteristic of colonial situations in general, the Japanese colonizers disregarded the value of local culinary culture in order to control and to maintain its position as supreme authority (Collingham 2006).

When Kuo-Ming Dong took its government into exile in Taiwan, the stratification between the foods of the colonizers and those of the colonized was also manipulated to create invisible and unspoken social and ethnic distinctions. The criterion for ranking culinary taste and cooking in postwar Taiwan was a reflection of the political interests and the ethnic hierarchy. ${ }^{1}$

Taiwan has been self-promoted as a gourmand society by virtue of the promotion of specific Chinese cuisines since 1945, during which time its cuisine has been manipulated to represent an epitome of Chinese culinary heritage. Indeed, many good chefs from families of the upperclass and the former nobility who also took refuge from the mainland with Kuo-Ming Dong brought a variety of regional Chinese gastronomic traditions to Taiwan. However, as far as ethnic food is concerned, the Mainlanders, as the dominant group, fashion the social discourse of gastronomic traditions, which presumes Mainlander cuisines to be more sophisticated than those of the native Taiwanese in terms of the gastronomic aesthetics, technique and language. To be sure, culinary discourse is very important in the formation of a community's culture, a fact that is exemplified in the creation of the French national cuisine in the seventeenth century. French national cuisine established its high reputation by means of a lexicalization of culinary terms and the formation of a specialized discourse (Ory 1997). Like French cuisine, Chinese gastronomy also has a specialized vocabulary in the discussion of dishes and food-associated knowledge. The Taiwanese vernacular is disdained by the political and cultural elites; as a consequence, the Taiwanese foods described in this vernacular are disqualified from prestigious gastronomic positions due to their cultural subordination and lack of gastronomic aesthetics. Whether true or false, this discourse has already been applied to the menus of high-end restaurants, the culinary market 
and the category of haute cuisine. In the past fifty years, it has been very rare to find Taiwanese cuisine on the menus of hotel restaurants, while other Chinese provincial cuisines - e.g. Zhe-Jiang or Guang-dong - have been common (Wu 2002).

How is this prejudicial culinary discourse consumed and internalized by Taiwanese natives? From January 2007 to May 2007, I conducted several informal and formal interviews with a few customers and hotel restaurant chefs in the capital city of Taipei and the second-largest city of Kaohsiung, focusing on the question of why Taiwanese foods are not as popular as other Chinese ethnic food in high-end restaurants (Lee 2006; A-Lan 2007; A-Hui 2007; Kuodong 2007). The majority of my interview subjects had the common idea that the popular Taiwanese foods are just street snacks. In addition, they held the stereotype that most of the native Taiwanese diet is considered too vulgar to be presented as part of national culture in museums, festivals and state banquets, until the Democratic Progressive Party (DPP) held an alternative banquet featuring native Taiwanese dishes for the presidential inaugural dinner in 2000. Their answers also show that while the impression and social standing of Taiwanese foods seem to have improved, the culinary discourse on ethnic foods and the praise for Mainlander cuisines remains undisputed in Taiwanese society.

This prejudice, indeed, still exists between ethnic groups. Mainlander foods are labelled as 'outsider' foods by other ethnic groups. In my interviews with Holo family members aged over forty years and living in rural areas or small cities, they recalled childhood memories of referring to Chinese Mainlander noodles, now commonly called Yang-Chun noodles (plain noodles) as Goa-seng min (out of the province noodles) as a distinction of their cultural unfamiliarity. ${ }^{2}$ The term Goa-seng min may not have a negative connotation, but it endorses a particular discrimination between the self and other communities. This terminology is subtly created as a tactic of resistance to the outsider at the inception of the encounter.

In Taiwan, of course, the distinctions between ethnic foods cannot be generalized as simply the dualistic opposition between Mainlanders and Islanders. Mainlander cuisine might not only refer to a united or single predominant entity, but to the many flavours that comprise the genealogy of Chinese gastronomy. In the orthodox cookbook of Chinese gastronomy, foods are classified into North Chinese cuisine and South Chinese cuisine (Anderson 1988). Taiwanese cuisine is included in the section on South Chinese cuisine. In Kuo-Ming Dong's political agenda, 
there are two paradoxical ideas: on one hand, Taiwan and China are seemingly linked in terms of cooking, language and cultural heritage; on the other hand, Taiwan's culinary culture and folklore are marginalized from the centre of power. Taiwan assumed a key role as a representative of the 'real' China, but remained merely a 'representative' and was denied a 'real' culture of its own. As a result, Taiwanese cuisine was forced to reposition itself as a regional style of Chinese food, in order to support an unspoken affirmation of Chinese national and cultural unity in the exile's imagination. In this way, the categorization of food is involved in the practice of dominator ideology. By selecting one cuisine as more refined or delicate, the cultural hegemony could manipulate the food market and people's appetites.

Due to the rough political transformations and historical distortions, the social distinction of taste in Taiwan is manipulated by a complex of political and economic powers. As a consequence, acquired tastes change more frequently in Taiwan than in other countries. As the stereotypical pictures display, Taiwanese native foods used to be represented as banal or even vulgar everyday diets, not delicate enough to be served at state banquets and formal national events. This social alienation between place and people, between culture and everyday life, was a common scene in the last century. Taiwanese native foodways were never defined as a national culture until the present decade. Nevertheless, some phenomena indicate that 'the assumed national delicacies' are being modified, most notably by the development of culinary tourism. Therefore, it attracts my interest to explore the ways in which Taiwanese foods have become visible in the national picture and serve as illustrations of a coherent Taiwanese national culture.

\section{The Increasing Visibility of Taiwanese Food}

If 'local food' is what local people eat in their everyday lives, tourists looking for an 'authentic' experience might expect to find popular local foods at any hotel restaurant. Taiwan, however, is unique in the fact that the popular local cuisine could not be commonly found on hotel restaurants' menus until the current decade. Chinese, Japanese and Western styles of food predominated at such high-end restaurants, while typical Taiwanese foods seemed ostracized to street vendors in marketplaces and low-end restaurants. The classification of foods into high and low cultures is a well-documented phenomenon. 
The social position of Taiwanese foods is internalized within the limits of economic possibility and impossibilities in the structure of the social space (Bourdieu 1984). In an analogical manner, social space is like a hierarchical showcase in which cultures are displayed in a ranked order. In fact, a glass ceiling was established to keep Taiwanese food in a lower position and even to make it invisible during high-level national events. By simply breaking the glass ceiling that has been set up by the practice of power relationships, the increasing visibility of Taiwanese food might be made possible.

\section{The Growth of Localism from the 1970s to the 1990s}

Localism has become the most important cultural policy in increasing the 'social inclusion' of minority cultures in contemporary Taiwan. The emergence of cultural policy was demanded by the rise of civil society and the democratization in Taiwan. As one can observe, the central and local governments promote folk arts and communities' cultures in response to this social request. This cultural policy also has great relevance to the development of cultural tourism, as it determines the reformation of public works and services in tourist attraction sectors (Butcher 2006).

The emergence of localism in postwar Taiwan began with and was developed by the endorsement of native-soil literature in the early 1970s. The spirit of native-soil literatures was to turn prevailing social concerns from their focus on the issue of Chinese liberation and the appreciation of Chinese culture to more tangible social resources and social realities in Taiwan. Portraits of everyday lives and the social problems encountered by ordinary people in Taiwan became fashionable subjects for native-soil novelists (Chen 1977).

In comparison to the native-soil novels, the literature in the $1950 \mathrm{~s}$ and 1960s reflects the fact that the mainstream ideology of the Literary Circle praised the prevailing value of modernism and the literati devoted efforts to emulate western cultures and to discuss abstract ideologies. Taiwanese modernist literature of the time was based on the idea of Western liberal-humanist traditions. Imposing the restrictions on speech, Kuo-Ming Dong implicitly compelled literati to fashion this particular style of literature as a way to avoid literary persecution. The writing of modernist literature, on the other hand, was directly supported by government funding in order to show the articulation between the legitimacy of its domination of Taiwan and the idea of Western modernity. This was taken as a political strategy to gain support from 
western societies, especially to sustain the affiliation of the United States (Chang 1993; Lu 1992). In this context, the native-soil literary movement is regarded as a modest declaration against this mainstream ideology that neglects the indigenous context by praising the prevailing value of modernism.

In addition, native-soil literature has been considered to be an alternative social movement advocating for the right to establish a Taiwanese cultural identity (Lin 1989). The native-soil literature movement was raised by the young intellectuals who were able to write well in Chinese and to deliver arguments against the necessity of Chinese nostalgia. Before this movement, the Mainlander group was the predominant group in the literati. It is not only because they controlled the cultural industry in terms of publishing, broadcasting and other mass media at that time, but also because of the massacre that began on 28 February 1947 and the successive political persecutions that were intentionally set up to prevent the spread of communist ideologies in the period of White Terror, which took the lives of many native elites (Kerr 1965). The fear made the majority of native Taiwanese avoid public speech and publishing.

In general, this literary trend was limited to the intellectual sphere, rather than becoming a wide-ranging social movement, but it still sheds light on the newfound value of local cultures and communities. In the 1990s, the rise of the grassroots movement challenged the Kuo-Ming Dong's authoritarian domination in a more concrete way and brought about substantial political reform for democratization and cultural liberation. However, during this transformation period, social discourse primarily focused on the issues of democracy and the formation of the Taiwanese nation-state. In contrast to the literary movement, the groups behind the political reformation paid relatively little attention to the revitalization of traditional Taiwanese culture.

Until the late 1990s, the discussion of local food culture was obviously trivialized and almost absent from the major forums of public debate. There were few articles in newspapers or cookbooks discussing the subject of food culture. In addition, native Taiwanese cuisine was not as popular a subject as other cuisines (Chiang 2001). Newspaper and cookbook articles from this period can be summarized by two typical narratives. First, Taiwanese cuisines are always presented as being limited to local agricultural products. This type of narrative implies that the uniqueness of Taiwanese cuisine predominantly relies upon the advantage of natural conditions for agricultural growth, rather than 
the excellence of its own gastronomy (Sinorama 1999). Second, as far as the cultural dimension of food is concerned, the narrative commonly focuses on the quality of Chinese cuisine in terms of its cooking techniques, preparation of individual dishes and presentation at the dining table (Song 1988; Fu 1987). ${ }^{3}$ These typical narratives were intentionally designed and distorted by a political agenda that promoted the idea that local food is merely ethnic in order to shed light on the greatness of Chinese food and culture. This agenda also misrepresented the Taiwanese identity as local and ethnic rather than national. Until the late 1990s, the Taiwanese diet was still positioned at the margin of the marketplace; in addition, there was little room for it in the newspapers.

Since then, however, the visibility of Taiwanese cuisine has increased. In keeping with broader international trends, this increased visibility mainly resulted from two significant and intertwined historical contingencies: one is the social trend towards democratization and the demand for the political acceptance of multiculturalism; the other refers to the increasing social demand for a reconstruction of identity by which cuisines can be identified as unique as artworks and other cultural products. In general, these Taiwanese social trends imply that food is being utilized as a symbol and a form of soft resistance to the subordinations of the past, the national identity crisis and especially the cultural alienation between local people and their 'immigrant-rulers'.

\section{The Preservation of Local Culture in the International Context} According to Lanfant's (1995) analysis of international tourism, many countries that were marginalized from the centre of the world economy by the end of the 1960s simultaneously attempted to transform into resorts for tourists from the great metropolises of the industrial world. This can be taken as the hallmark of the development of international tourism in the Third World countries. For example, the Indonesian government, with the aid of the World Bank and foreign consultants, decided to make Bali the greatest focus of its tourism development. The turning point in this international development came about when the large industrial countries (LICs) were faced with a world economic crisis in the 1980s and 1990s. During this time, governments used greater involvement in tourism policy as a means of resolving the economic difficulties cropping up in certain areas of their countries (Lanfant 1995). Of course, this governmental involvement caused local tourism to become organized on a broader global scale. In addition, options for tourism in the local region began to expand in the wake of this global strategy. 
Whether this strategy was adopted by state governments alone or in conjunction with international political, economic or cultural organizations, it was all undertaken, as Lanfant argues, 'within the context of plural and/or supranational institutions' (Lanfant 1995: 2). In that sense, the nation-state's important role is reasserted. The notion of nation-state can be considered as the basis for understanding how the local rises to the level of a world culture via the increasing interconnection within/ between nation-states. Furthermore, the conceptualization of local is heavily affected by the development of the local tourism industry, which involves not only intra-structural interaction within a nation-state but also the political economic competitions between nation-states.

When the Taiwanese tourism industry is compared with that in other countries, it is interesting to question why the Kuo-Ming Dong government did not make a full effort to participate in this global trend, either during the first wave of the 1960s or the second wave of the 1980s. Was it because Taiwan, as a semi-periphery country in Wallerstein's (1974) logic of the world system, at that time had better opportunities in industrial development than in tourism?

From above, the international perspective attributes tourism policy to economic decisions made in response to the transformation of the global economy. When the industrial sectors of developed countries began to shift to developing countries, the abandoned regions of developed countries and the still-neglected regions of underdeveloped countries were simultaneously seeking economic opportunities. The shift in industrial centres gave rise to the idea of localism by creating scenarios of uneven domestic development in both developing and developed nations, which caused the neglected local communities in all countries to advocate for their own economic opportunities, and thereby, their own local identity. However, this approach does not provide a convincing explanation for why the identity of the local is shifting.

The concept of the local is shifting, along with the interactions between the self and the other as they concern communal and national identity, e.g. interaction between Taiwan and the other industrial countries. The notions of self/other cannot remain fixed in either time or space. In a sense, there might be many different others appearing at different points in time and space; as a result, various boundaries are outlined within which individual identities are created. This shifting of self and other is much like the relationship between Taiwan and China. Amid changing social conditions, the definition of Chinese and Taiwanese is transforming from a vertical domination/subordination relationship 
to a parallel international relationship. Precisely, Taiwanese identity is shifting from a reflection of China to indigenization. Thus, in order to understand the increased visibility of Taiwanese-ness, it is necessary to examine the social conditions that gave rise to the transformation of Taiwanese national identity.

This transformation began in the late 1980s, when Taiwanese businessmen started seeking business opportunities in China. In 1987, Taiwanese authorities loosened the restrictions on foreign currency exchange and gave permission for Mainlanders to return to China to visit their families. This marked a milestone in the previously standoffish, non-negotiable relationship between Taiwan and China since the communist victory in the Chinese civil war of 1949. In the last twenty years, many Taiwanese businesses, mostly in labour-intensive industries, have moved their investments to Mainland China because of the supply of low-cost workforces. Although Taiwan's government has imposed heavy restrictions on trade with and investment in China, it could not prevent large amounts of money from flowing into a now-opened China. According to the Ministry of Economic Affairs' records, approved investments in China were valued at US\$65 billion from 1991 to 2007 (Yee 2008). Even this figure does not provide an accurate picture, because 'the strict rules had forced the companies to use loopholes, like investing through shell companies in third [party] countries' (Landler 2001).

Obviously, the more businesses migrate to China, the higher the identity crisis rises in Taiwan. Precisely, when China opens its doors to sell the so-called Chinese national cuisines as its cultural heritage to the world, it is considered to be the major economic competitor and political opponent of Taiwan. The previous undefined and ambiguous relationship between Taiwan and China has resulted in the enormous loss of economic profits and a national identity crisis for Taiwan. Therefore, it is necessary to reconsider the Taiwanese future, whether to be or not to be the self-pretended successful Chinese heritage reserve zone.

On the other hand, under such crises, an increasing number of Taiwanese people become more eager to establish their own cultural identity and confidence, and become more enthusiastic about discovering where and what authentic Taiwanese cuisine still flourishes in the local cultures. The increasing interest in foods also drew public attention to a further quest for discovering traditional ethnic cultures in Taiwan as well as a more general Taiwanese identity. To a great extent, this increasing social appreciation of local culture and history is tacitly undertaken as a soft resistance against the Chinese cultural hegemony. 


\section{The DPP Government's Agenda on National Cuisine}

In 2000, the Democratic Progressive Party won an election for the first time in Taiwanese history and started to design brand-new menus for state banquets. Because Taiwanese cuisine had been neglected by the state and ruling elites, there was not a so-called 'Taiwanese dish' to be presented as such during state banquets. Under Japanese colonialism, Japanese and French cuisines were commonly served to foreign delegations. Taiwan's local fruits and agricultural products were merely used to display the triumph of colonization. During Chiang Kai-shek's regime in Taiwan (1949-1975), the leader's favourite dishes could be found among the Chinese Zhe-Jiang cuisine, and these were the courtly dishes presented at state banquets (Appendix I). His son, Chiang Chin-Kao, the second president of Taiwan (1975-1988), had some appreciation for the local Taiwanese cuisines from his travels around the island. However, being prudent, he never considered any Holo, Hakka and Aboriginal dishes as appropriate to be served on formal occasions. His successor, President Lee Teng-hui (1988-2000), predominantly employed Chinese Guang-dong cooking (Wu 2002) ${ }^{4}$ and accepted the established gastronomic discourse regarding the hierarchy of Chinese and local Taiwanese cuisines (Fu 1987; Chen 1991).

The DPP government was the first to challenge the Kuo-Ming Dong's tradition and the Grand Hotel's monopoly on state functions. ${ }^{5}$ During Chen Shui-bian's presidency (2000-2008), many of his state dinners were prepared by chefs from other restaurants without experience in catering state banquets. He has held two inaugural banquets and about forty state banquets with foreign leaders and delegations in different cities all over the island (Office of President 2007). As for the menus of these state dinners, all of them were specially designed to incorporate local foods as ingredients - e.g. aboriginal millet from Eastern Taiwan, Haka ethnic flavours from Southern Taiwan, milkfish ball from the local seaport, wa-guei from President Chen's hometown, and other humble snacks from different ethnic groups and regions (Appendix II) - a tactic meant to demonstrate a policy of multiculturalism and decentralization to the people and the nation's guests. Afterwards, the dishes served at state banquets are sold in markets aimed at both domestic and international tourists (Lee 2006). Restaurant managers consider this practice a way to expand business; the government regards it as an alternative to the declining industrial economy. This change can be viewed as a prominent sign that the DPP government is attempting to eliminate the previously subordinate image of Taiwanese cuisine through the decentralization 
of Chinese cultural hegemony and the promotion of domestic culinary tourism for the local economy.

\section{Culinary Tourism in Taiwan}

What is culinary tourism? Easy answers include a journey for which food is the focal interest, or travel by tourists whose primary aim is to taste something different. Of course, we can understand that culinary tourism is often combined with other aspects of tourism, and that tourists who are not on explicitly culinary adventures must also eat. Culinary tourism is a relatively new phenomenon; it is distinctive in the sense that foods themselves have become the attraction and inspiration for some tourists' journeys. There is a type of culinary tourism interested in nothing else but food; the sole purpose of travel is eating various foods. There are also types of culinary tourism that can be practiced in everyday life without the need for physical travel (Long 2004). For instance, cooking exotic foods at home or consuming foods at local restaurants could be the simplest ways to participate in such popular activities.

The culture of culinary tourism, to be sure, can be extended to incorporate the complexity of the culture of mass consumption, as well as aspects of food production: e.g. the self-organized or agent-arranged itineraries featuring wineries, authentic restaurants, farms, food factories, festivals and so on (Kirshenblatt-Gimblett 2004). For this paper, culinary tourism will refer to the social phenomenon of people travelling for the explicit purpose of tasting foods.

The development of culinary tourism has been supported by the increasing convenience of transportation, economic growth, the dissemination of the ideology of leisure and the public's increased desire to consume others' culture (Heldke 2003; Long 2004). Western countries have ignored culinary tourism for a long time in comparison to Asian countries. The rise of culinary tourism as a trendy leisure activity could be attributed to the promotion of local cultures (MacCannell 1999; Urry 1990; Mintz 1996), in addition to the idea that food can represent local cultures.

In Taiwan, tourists' demands for authentic local foods have resulted in a reinterpretation of what native Taiwanese cuisine is or should be. Dishes once considered the everyday nourishment of average working class people have suddenly been given a new elevated status. This reinterpretation process is made possible by the presence of a 
'visitor' who views everyday objects with novelty. In Veverka's words, '[i]nterpretation is a communication process designed to reveal meanings and relationships of our cultural and natural heritage to the visitors through first-hand experiences with objects' (Veverka 1994: 19, cited in Puczkó 2006). Applying this notion to the Taiwanese case, it is clear that this reinterpretation of the uniqueness of Taiwanese cuisine has created a cultural attraction for tourists. However, one might ask why it is necessary to reinterpret the meanings and values of Taiwanese cuisines, and who is capable of engaging in such an interpretation. The question can be simply answered by observing Taiwan's social transformation; whereas the 'old' Taiwan had an ambiguous relationship with Chinese culture and history, the new Taiwan defines itself as ethnically and culturally distinct from China.

\section{Governmental Involvement in the Development of Culinary Tourism}

The economic flight to China signified a turning point at which Taiwan began to reassess its own economic structure as it shifted from industrial production to the service, information and technology sectors. It was also the point at which the Taiwanese government began investing heavily in its tourism sector. The development of culinary tourism has gained support and advantages from this governmental participation. According to official reports, there are at least ten festivals, local and national, associated with food and gastronomy that have been annually sponsored by the government (Tourism Bureau Online 2008). However, there has also been strong criticism of the government's inefficiency in promoting and developing the tourism sector. Industry professionals complain that the formulation of the government's tourism policy is always belated and unable to catch up to the developing market. An interviewee, Mr. Chen, who is a member of the self-government committee of the Kaohsiung Night Market, indicates that

the night market has been unofficially considered an attractive sightseeing and shopping place for inbound tourists. Local individual hosts used to bring their guests and friends to pay a visit to the night market. Those visitors gave some similar feedback: they experience exotic and interesting local cultures at the night market, but somehow they won't spend more money on consuming food due to the poor environment and the unpleasant setting (Chen 2007).

Volunteer committee members complain that the authorities don't have any concrete plans for the environmental development of local 
night markets in general; instead, a self-government committee has to take care of the market's management and planning itself.

Taiwan considered itself a gourmand society even before the government's sponsorship. However, night markets have not been promoted as international tourist attractions until recent years. The government's ignorance of this resource is obviously shown on the Annual Survey Report of the Tourist Bureau. Before 2002, a survey questionnaire on sightseeing attractions for foreign tourists in Taiwan did not including the item 'night markets', but only the item 'food' in general (Tourism Bureau 1998-2006). This indicates that the authorities did not acknowledge the night markets' economic potential or status as Taiwanese cultural symbols. When a series of official guidebooks and maps were published to promote night markets all over the island, the central and local governments began to follow the tourism industry's advice in creating effective economic policies. As a result, the Tourism Bureau has become more proactive in promoting and sponsoring communities' events and food festivals at the local and national levels.

A project called 'One Town, One Product' (OTOP) illustrates the way in which the local and central governments initiate local activities to generate development opportunities for local businesses and communities (SMEA 2008). According to the Tourism Bureau's description, the OTOP program assists local industries in finding their unique cultural products. A series of guidance projects are designed to stimulate the development of local cultural enterprises. Featured industries and enterprises in each community can promote their existing local resources and cultural products for consumption by tourists (SMEA 2008). Food, as the major cultural resource in many locations, is considered to play a key role in this remaking of communal culture. In this sense, culinary tourism functions as a double-edged sword, resolving the problem of economic recession on one hand and constructing the communal identity on the other.

The Taiwanese government has sponsored many food festivals on the local and national levels since its acknowledgment that a particular kind of social transformation is taking place, i.e. the decline of agriculture and the resulting decay of the local community, which might create many serious social problems for society as a whole. Therefore, the leisure industry is being considered as a potential and important economic sector in the transformation of consumer society. ${ }^{6}$ 


\section{Mass Media's Effect and the Public Quest for Authentic Food}

The mass media's bombardment of advertisements and news reports is considered the most influential catalyst for the growing fanaticism for authentic Taiwanese delicacies. In a type of endless cycle, the media's discovery of authentic local cuisines has caused the public to crave authentic Taiwanese foods more than ever. In other words, the influence of mass media has been noticed and, to a large extent, exploited by food stores, restaurants and the food industry in general.

The relationship between mass media and the food industry as its patron is one based on enormous profits. Compared to other indigenous industries in Taiwan, most of which focus on original equipment manufacture and are export-oriented, the food industry is relatively small but significant in terms of branding. It therefore must rely on the media's services more heavily than other industries. Due to this peculiar economic structure, the media play an influential role in the process of making Taiwanese food culture and culinary tourism. This is the prevailing phenomenon that we observe: the food industry and tourism industry go hand-in-hand in exploiting the effects of the media.

The notion of authenticity is also abused by the way in which the food industry advertises itself. For instance, there are many different stores that feature banners bearing the title, Diyichia (First House or Original Store), throughout Taiwan. Actually, the majority of the stores are not the initiators, but have misappropriated the banner of 'First House' to attract customers. However, nobody has criticized this behaviour as a type of cheating; rather, it is viewed as a sort of advertisement. This highlights an ambiguous and ambivalent element in the consumers' psychological complexity. For customers, the doubt that any authentic foods actually still exist is part of what has made people become more and more eager for authentic foods. Once again, it seems to be a psychological cycle without any escape.

Or perhaps it is the case that tourists do not care about food but do care about having authentic experiences. As MacCannell (1999: 101) states, the 'touristic consciousness is motivated by its desire for authentic experience.' Tourists identify themselves through the actions of sensing, tasting and even imagining. They need material objects or an abstract purpose to pursue; therefore, the notion of authenticity comes into play. However, 'the flavour of authenticity' can probably be recreated at the moment of tasting, without the tourist's realizing that what he tastes is merely the image of authenticity and not authentic in itself. 
In this sense, I wonder what Walter Benjamin's assessment of culinary tourism might have been (Benjamin 1969). If the aura of authenticity could be restored and reproduced, then consumers could taste the aura of authentic food as they imagine it. Even though we know the authentic food we desire is merely an imagined picture on an empty canvas, and it is made and constantly manipulated by the powers that operate the mechanisms for the reproduction of authenticity, our hearts will never forget the loss of the authentic. This is the psychological complex that has been fully abused by the food industry and its accomplices.

From the simplified logic of supply and demand, when the anxiety for an authentic ethnic restaurant and gastronomic experience becomes the most significant concern in contemporary travel experiences, the demand for the traditional cooking and the hidden ethnic cuisines is meanwhile stimulated by this endless anxiety. In addition to the business concerns of the media and food industry, there is a functionalist perspective on food cultures that views the development of culinary tourism as an opportunity for the revitalization of traditional Taiwanese cooking. Precisely, when restaurants and food stalls compete to praise their own authenticity and uniqueness, it not only brings about fierce business competition, but also benefits the restoration of the vanishing traditional ethnic foods.

\section{Banal Foods Recaptured by the Touristic Gaze}

When I approached the food vendors at the night market in Kaohsiung city, they initially gave the impression of indifference towards their business: 'There is nothing special for me in going into business as a food vendor. What I have done is all about making money' (Song 2006). Apparently, the majority of these vendors were unable to find more valuable jobs or meaningful lives for themselves. They seemed only superficially aware of social change as their income increased or decreased through periods of economic growth or recession.

Then, however, I pointed at the photocopies of magazine articles and newspaper reports in front of their concessions like 'ZAGAT' signs in the windows of high-end restaurants. I would usually ask, 'What is this? Is this you and your concession?' Most of my interviewees would suddenly light up with splendid smiles. I found that through these pictures and reports they could easily make themselves forget their hectic jobs and begin to discuss their foods, markets and life stories. They seemed happier to introduce the profiles of foods and themselves in the photos and even extolled that they are serving the best foods of this night market. ${ }^{7}$ 
Frankly, their responses do not surprise me, but I was amazed that their attitudes could be shifted so quickly. I wonder how they could present different answers to the same question within such a short time span. Was it because the communication context had moved from a shared reality to an alienated and in some way idealized picture? It is undeniable that looking at one's self as it is projected onto an external medium can cause commonplace things to seem brand-new and different.

Perhaps the foods still have the same flavours, but the people have started to identify and reinterpret the meanings and values of the foods they serve. In a sense, I would claim that the touristic gaze - as a viewpoint originating from outside one's community and one's self-has the powerful psychological effect of changing the mindset of both the beholder and the beheld, allowing both to look at banal street snacks in a whole new light. Indeed, the creation of distance between imagination and reality and dialogue between uniqueness and everyday life is a powerful agent in overturning the colonizer's viewpoint and changing the image of Taiwanese food and its inferior social standing.

\section{Conclusion}

In this paper, I have illustrated the issue of identity formation and social transformation as it relates to the development of culinary tourism in contemporary Taiwan. It would be difficult to miss the significance of culinary tourism when paying a visit to Taiwan. Nevertheless, it is easy to ignore the social implications of this growing tourist culture and industry that go beyond the phenomenon of leisure activities. Culinary tourism has developed out of social transformations in Taiwan such as the acceptance of localism, the growing impact of mass media and the increasing governmental involvement in cultural activities.

My primary approach to the social construction of food culture in relation to Taiwanese social transformation expressly underlines the fact that the sociology of culture has turned its focus towards the role of symbolic representation. The Taiwanese focus on cuisine demonstrates that what we call 'the cultural turn' in the social sciences is not limited to academic contexts; rather, it is also a practice by which a culture reflects on itself. Food as the symbolic representation of culture has its own substantial economic value, as well as a symbolic value fashioned by the practice of production and consumption. Therefore, in this paper, I have shown that Taiwanese foods are utilized as a symbol and a kind of soft resistance to the subordination of the past, as a response to the 
national identity crisis, and especially to overcome the cultural alienation between local people and their immigrant-rulers.

Hui-Tun Chuang is a PhD. Candidate of New School for Social Research, New York.(Chuah427newschool.edu/autumchuang@gmail.com).

\section{Appendix I: The menus of state banquets in Chiang Kai-shek's regime ${ }^{8}$}

1. Plum blossom assorted cold dishes, including spiced tendon, steamed egg, mushroom, vegetable chicken

2. Yang-Chuo fried rice or Yi-fu fried noodle

3. Beef bun or dumpling (Bao-zi)

4. Fish-fin soup in casserole

5. Abalone soup

6. Bamboo seafood soup

7. Sweet and sour fish

8. Curry dumpling

9. Shrimp spring roll

10. Cabbage hearts with mushroom

11. Date paste pancake

\section{Appendix II: 2000 Inaugural Banquet of the Tenth-term President of Taiwan}

\section{A. Spring Burgeoning:}

1. Salmon, Scallops and Salmon Eggs Salmon (Origin: Deep sea fishing); Scallops (Origin: Deep sea fishing); Salmon eggs (Origin: Deep sea fishing).

B. Summer Nurturing :

2. Milkfish Ball Soup Milkfish paste (Origin: Tainan/Natural taste: sweet/Character: moderate); STUFFING Bamboo Shoots (Origin: Chiayi, Yunlin).

3. Tainan Style Rice Cake Tsai-Lai rice paste (Origin: Taiwan); STUFFING Fragrant Mushrooms (Origin: Taiwan); Small dried shrimp (Origin: Taiwan.)

C. Autumn Grace:

4. Steamed Lobster with Spring Onions and Ginger Lobster (Origin: Auti)

5. Smoked Cod Fish Cod fish(Origin: Deep sea fishing).

6. Mutton chop Roast Mutton Chop (Origin:Kangshan).

D. Winter Nourishment:

7. Taro \& Sweet Potato Sponge Taro (Origin: Shiahsien, Taiwan); Sweet potato (Origin: Chinshan, Taiwan); Tsailai rice powder (Origin: Chianan Plain).

8.Glutinous Longan Gongee Chinese Jujube (Origin: Miaoli, Taiwan); Longan (Origin: Chianan); Lotus seed (Origin: Tainan's Paiho ); Glutinous rice (Origin: Chianan). 


\section{NOTES}

1 According to the official census, the Taiwanese people consist of four major ethnicities: the Aboriginals, Hakka, Holo (the first three groups to settle the island, all arriving before the Second World War) and the Mainlanders (who arrived from China after the Second World War). Strife among Taiwan's ethnicities is notorious because each different ethnic group occupies an uneven political status that entails varying degrees of access to economic resources.

2 These personal interviews were conducted in Kaohsiung and Taipei from January 2006 to March 2006 and also from January 2007 to May 2007.

3 Before 1995, it was common to find the recipe books with such titles as 'Taiwanese-style Chinese cuisine' or 'a local style of Chinese cuisine'. For instance, a local institution such as the Wei-Chuan Cultural-Educational Foundation also promoted the notion that Taiwanese cuisines have numerous similarities with Chinese.

4 Guang-dong cuisine was fashionable in the late 1990s.

5 As for the operation of the state banquet, the Grand Hotel served as the 'royal' restaurant and was officially in charge of catering all state banquets.

6 When the Taiwanese government gave out special titles for 2004-2005, the 'Taiwan Tourist Year', and 2008-2009, the 'Tour Taiwan Year', it declared that tourism was becoming an important economic sector.

7 In February 2007, I interviewed ten people at Liuo-ho night market, Kaohsiung. Texts are translated from Taiwanese and have been paraphrased.

8 These are Chinese flavored dishes derived from the Mainland Chinese gastronomic style. Curry dumplings and date paste pancakes were Madam Chiang's favourite.

\section{REFERENCES}

A-Hui, Da Chu 2007. 'Restaurant Chef '. Interview by author. Tape recording. Taipei, Taiwan, 9 May 2007.

A-Lan, Er Chu 2007. 'Restaurant Chef'. Interview by author. Tape recording. Taipei, Taiwan , 15 April 2007.

Anderson, B. 1983. Imagine Communities: Reflection of the Origin and Spread of Nationalism. New York: Verso.

Anderson, E. N. 1988. The Food of China. New Haven: Yale University.

Appadurai, A. 1988. 'How to Make a National Cuisine: Cookbooks in Contemporary India'. Comparative Studies in Society and History 30 (1): 3-24.

Benjamin, W. 1969. 'The Work of Art in the Age of Mechanical Reproduction'. Illumination: Essays and Reflections. New York: Schocken Books.

Bigelow, P. 1923. Japan and her Colonies: being extracts from a diary made whilst visiting Formosa, Manchuria, Shantung, Korea and Saghlin in the year 1921. London: Edward Arnold \& Co.

Bourdieu, P. 1984. Distinction: A Social Critique of the Judgment of Taste. Cambridge, MA: Harvard University Press.

Butcher, Jim 2006. 'Cultural Politics, Cultural Policy and Cultural Tourism'. In M. K. Smith et al. (eds.). Cultural Tourism in a Changing World: Politics, Participation and (Re)presentation. New York: Channel View Publication: 21-35.

Chang, S. 1993. Modernism and the Nativist Resistance: Contemporary Chinese Fiction from Taiwan. Durham, NC: Duke University Press.

Chen, Chi-Lu 1991. 'Forward' in L. H. Lin (ed) Chinese Cuisine Taiwanese Style. Taipei, Taiwan: Wei-Chuan Cultural-Educational Foundation. 
Chen, Xian-Shen 2007. 'Member of the self-government of Kaohsiung Night Market'. Interview by author. Tape recording. Kaohsiung, Taiwan, 30 January 2007.

Chen, Ying-Chen 1977. 'Wenxue laizi shehui fanying shehui' [Literature comes from society and reflects society]. In Yu Tiancong (ed) Xiangtu wenxue taolunji [The debate on native-soil literature]: 53-68.

Chiang, Y. 2001. The Transition of Food Culture on Food Pages in Taiwan Press: A Case Study of China Times and Min Sheng Daily. M.A. thesis, Taipei: Ming Chuan University Graduate School for Communication Management (thesis in Chinese).

Ching, L. T. S. 2001. Becoming Japanese: Colonial Taiwan and the Politics of Identity Formation. Berkeley, CA: University of California Press.

Cole, Stroma 2006. 'Cultural Tourism, Community Participation and Empowerment'. In M. K. Smith et al. (eds.). Cultural Tourism in a Changing World: Politics, Participation and (Re)presentation. Tonawanda, NY: Channel View Publication: 89-103.

Collingham, L. 2006. Curry: A Tale of Cooks and Conquerors. Oxford University Press.

Cook, R. 2001. 'Robin Cook's chicken tikka masala speech'. guardian.co.uk. Available from http://www.guardian.co.uk/world/2001/apr/19/race.britishidentity (accessed 8 January 2007.)

Cusack, Igor 2000. 'African Cuisines: Recipes for Nation-Building'. Journal of African Cultural Studies 13(2): 207-25.

Elias, N. 1982. The History of Manners. The Civilizing Process Vol. 1. New York: Pantheon Books.

Ferguson, P. 2004. Accounting for Taste: A Triumph of French Cuisine. Chicago: University of Chicago Press.

Finkelstein, J. 1989. Dining Out: A Sociology of Modern Manners. New York: New York University Press.

Fleischauer, S. 2007. 'The 228 Incident and the Taiwan Independence Movement's Construction of a Taiwanese Identity'. China Information. Available from http:/ / cin. sagepub.com/cgi/reprint/21/3/373 (accessed 18 March 2009).

Fu, PeiMei 1987. Pei Mei's Chinese Recipes. Taipei: Hong-li publishing.

Goody, J. 1982. Cooking, cuisine, and class: a study in comparative sociology. New York: Cambridge University Press.

Heldke, L. M. 2003. Exotic Appetites: Ruminations of a Food Adventurer. New York: Routledge.

Kerr, G. 1965 Formosa Betrayed. Boston: Houghton Mifflin.

Kirshenblatt-Gimblett, B. 2004 'Foreword' in L. Long (ed) Culinary Tourism. Lexington: University Press of Kentucky: xi-xiv.

Kuodong, C. 2007. 'Restaurant Chef'. Interview by author. Tape recording. Taipei, Taiwan, 9 April 2007.

Landler, M. 2001. 'Taiwan Lifts Restrictions on Investment in China'. New York Times (Online). Available from http:/ / query.nytimes.com/gst/fullpage.html?res=9904E 1DC1E39F93BA35752C1A9679C8B63 (accessed 23 September 2008).

Lanfant, M., J. Allcock and E. Brunner (eds.) 1995. International Tourism: Identity and Change. London: Sage Publications.

Lee, Y. 2006. 'Hotel Manager'. Interview by author. Tape recording, Taipei, Taiwan, 20 February 2006.

Lin, ChenGhuang 1989. '"Taiwan wenxue yu "Taiwan yishi chuyi"' [A modest discussion of 'Taiwan literature' and 'Taiwan consciousness']. Taiwan yanjiu jikan [Taiwan research quarterly] 26: 69-73.

Long, L. 2004. 'Culinary Tourism: A Folkloristic Perspective on Eating and Otherness'. In L. Long (ed) Culinary Tourism. Lexington: University Press of Kentucky: 20-50.

Lu, Z. 1992. Chanhou Taiwan wenxue jingyan. [The historical experience of Taiwan lit- 
erature since World War II]. Taipei: Xindi wenxue.

MacCannell, D. 1999. The Tourist: A New Theory of the Leisure Class. Berkeley: University of California Press.

MacLeod, N. 2006. 'Cultural Tourism: Aspects of Authenticity and Commodification.' In Melanie K. Smith et al. (eds.). Cultural Tourism in a Changing World: 177-90.

Mennell, S. 1985. All Manner of Food: Eating and Taste in England and France from the Middle Ages to the Present. Oxford: Blackwell.

Mintz, S. 1996. Tasting Food, Tasting Freedom: Excursion into Eating, Culture and the Past. Boston: Beacon Press.

Office of President (Taiwan) 2007 'State Banquet.' Available from http:/ / www.president.gov.tw/1_art/act/banquet.html (accessed 3 January 2007).

Ooi, C. 2002. Cultural Tourism and Tourism Cultures: The Business of Mediating Experiences in Copenhagen and Singapore. Copenhagen: Copenhagen Business School Press.

Ory, P. 1997. 'Gastronomy'. In P. Nora (ed) Realm of Memory: The Construction of the French Past. New York: Columbia University Press: 443-68.

Peterson, R. 1997. Creating Country Music: Fabricating Authenticity. Chicago: University of Chicago Press.

Pilcher, J. 1998. Que vivan los tamales: Food and the Making of Mexican Identity. Albuquerque: University of New Mexico Press.

Puczkó , L. 2006. 'Interpretation in Cultural Tourism'. In M. K. Smith and M. Robison (eds.) Cultural Tourism in a Changing World: Politics, Participation and (Re)presentation. New York: Channel View Publication: 227-43.

Shih, C. 2002. 'Ethnic Identity and National Identity'. Paper presented at Taiwan Roundtable Forum: Human Rights in Taiwan and the Mission of the Church in Response Thereto, organized by Presbyterian Church Taiwan, Taipei, December 12-13.

Shiunaigashi 1909. 'Shi Chang Da Kuan' [The Impression of Taiwan's Market]. Fa Yuan Yue Bao [Court Monthly Report] 3:1.

Sinorama 1999. 'Seafood: Taiwan's Undersea Treasure'. Sinorama February 7-15.

SMEA 2008. 'Taiwan One Town One Product'. Ministry of Economic Affairs (Online). Available from http:// otop.tw/ (accessed 15 July 2008).

Song, D. 1988. Recipes for Taiwanese Cuisine in the series of Chinese Local Foods. Taipei: Han-Kuang.

Song, M. 2006. 'Vender of Kaohsiung Night Market'. Interview by author. Unpublished Notes. Kaohsiung, Taiwan, 28 January 2006.

Tourism Bureau 1998-2006. Annual Survey Report on Visitors Expenditure and Trends in Taiwan. Taipei: Tourism Bureau, Ministry of Transportation and Communications.

Tourism Bureau Online 2008. Welcome to Taiwan. Available from http:/ /eng.taiwan. net.tw/lan/Cht/news_event/events_all.asp (accessed 15 July 2008).

Urry, J. 1990. The Tourist Gaze. Thousand Oaks, CA: Sage Publications.

Wallerstein, I. 1974. The Modern World-System. New York: Academic Press.

Wang, WeiChung 2008. Wei Chung jie jie de Chian Chuan Tsai. [Wei-chung sister's Chian Chuan Cooking] Taipei: Shi Pao Wen Hua [China Times] Publishing.

Wu, David 2002. 'Cantonese Cuisine (Yue-cai) in Taiwan and Taiwanese Cuisine (Tai-cai) in Hong Kong'. In D. Wu and S. Cheung (eds.) The Globalization of Chinese Food: 86-99.

Yee, L. 2008. 'Taiwan 2007 investments in China'. Reuters India (Online). Available from http:/ /in.reuters.com/article/asiaCompanyAndMarkets/idINTP26278020080121 (accessed 22 September 2008). 